\title{
Do trainers pay enough attention to posture adjustment when athletes perform strength exercises in a leg press machine?
}

Marta Castaner ${ }^{\text {a }}$,

Hristo Novatchkov ${ }^{b}$,

Ruben Orejon ${ }^{c}$,

Desiree Vilas ${ }^{d}$,

Suggested Citation:

New Trends and Issues

Proceedings on Humanities and Social Sciences.

Abstract

Marta Castaner , 
Sciences.

\section{Introduction}

1.1. Aims

2. Method

\subsection{Participants}

6,15

$M=31,70 ; D T=$

2.2. Instruments 
Sciences.

\section{Results}

\section{Interpretation}

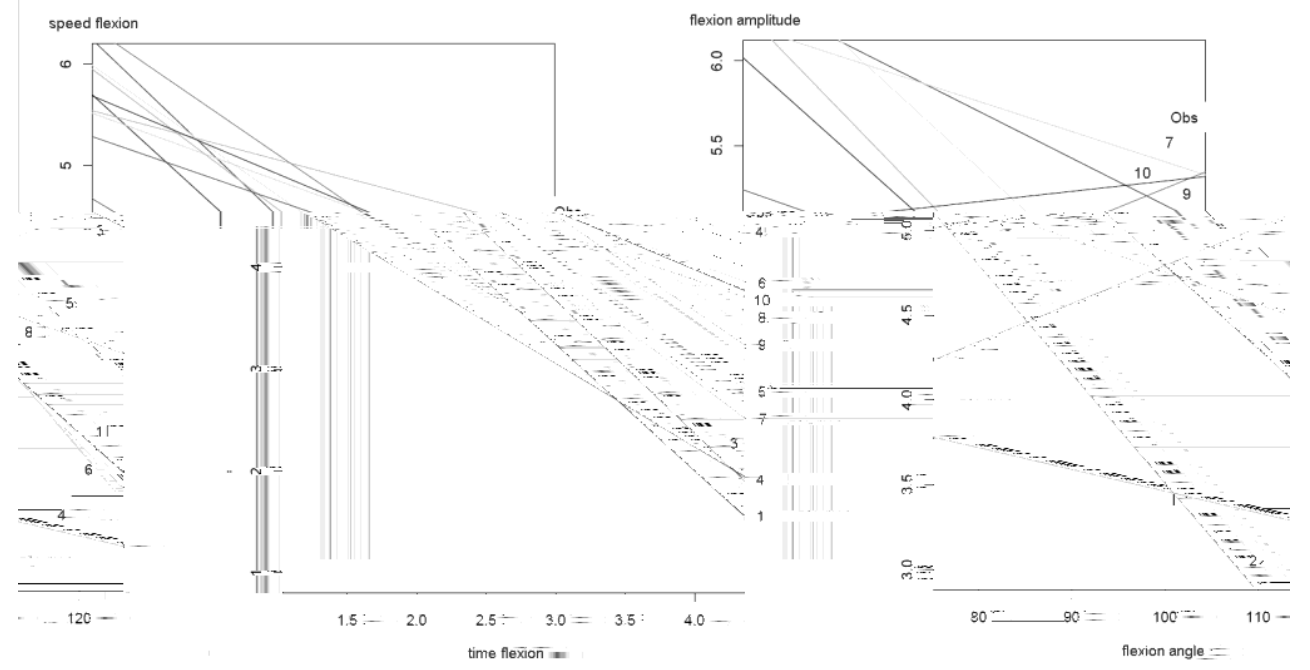

Figure 1. a) Regression analysis for the variables time and speed of flexion; (b) regression analysis for the variables amplitude and angle of flexion. 
Sciences.

\section{Conclusions}

\section{Acknowledgments}

\section{References}

Behavior Research Methods. 41

Proceedings of the 7 th International Conference on Methods and Techniques in Behavioral Research Proceeding 10

Sports Science \& Medicine, 12

International Journal of Computer Applications, 71

ACSM's Health \& Fitness Journal, 13 